\title{
CONTEMPORANEOUS AND LAGGED CAUSAL RELATIONSHIPS AMONG NEGOTIATED LIVE CATTLE CASH MARKETS
}

\author{
BRIAN K. COFFEY* \\ Department of Agricultural Economics, Kansas State University, Manhattan, Kansas \\ DUSTIN L. PENDELL \\ Department of Agricultural Economics, Kansas State University, Manhattan, Kansas \\ GLYNN T. TONSOR \\ Department of Agricultural Economics, Kansas State University, Manhattan, Kansas
}

\begin{abstract}
U.S. live cattle markets have experienced dramatic shifts in marketing methods over the past two decades, changing the way live cattle prices are discovered. We identify relationships between prices of the five major live cattle marketing regions using Granger causality and directed graph analysis. The two approaches complement each other and reveal that interweek and intraweek price discovery roles for given markets differ. Evidence indicates that Colorado, though a minor market in terms of relative volume, has become an important source of interweek price information to other markets.
\end{abstract}

Key words. Directed graphs, error correction model, live cattle, price discovery

JEL Classifications. Q110, Q020

\section{Introduction}

Live cattle ${ }^{1}$ markets and marketing methods have changed dramatically over the past two decades and continue to evolve (Parcell, Tonsor, and Schroeder, 2016). One of the most notable changes has been the decline of live cattle sold in the cash market via negotiation. Many industry participants and analysts have expressed concern that the price discovery work in negotiated markets is essential

U.S. live cattle markets have experienced dramatic shifts in marketing methods over the past two decades, changing the way live cattle prices are discovered. We identify relationships between prices of the five major live cattle marketing regions using Granger causality and directed graph analysis. The two approaches complement each other and reveal that interweek and intraweek price discovery roles for given markets differ. Evidence indicates that Colorado, though a minor market in terms of relative volume, has become an important source of interweek price information to other markets.

*Corresponding author's e-mail: bcoffey@ksu.edu

1 The term live cattle is used to denote all beef steers and heifers that have reached the desired weight for slaughter. The terms fed cattle, fat cattle, and slaughter cattle are used interchangeably with the term live cattle in many of the studies cited. 
to connecting prices to economic fundamentals and that the decline of negotiated purchases is detrimental to live cattle price discovery for the broader market (Schroeder, Tonsor, and Coffey, 2018). As the number of cattle in negotiated markets has declined, the number marketed using some manner of formula-based pricing has increased. Formula pricing requires a base price to which various premiums or discounts are added, depending on the specific agreement. The base price is derived from some existing price and is not negotiated. One convenient source of base prices is recent negotiated cash prices. This relationship between negotiated and formula prices has caused further concern as there is fear that cattle in the thinning negotiated markets may not be representative of cattle in formula markets, which are marketed with the goal of gaining premiums for having certain carcass traits. Given these concerns and the ever-evolving live cattle markets, understanding how different negotiated markets for live cattle interact with and affect each other through exchange of information is essential to understanding live cattle price discovery.

There is an extensive body of research on live cattle price discovery. A large share of attention has been devoted to the relationship between live cattle cash prices and the Chicago Mercantile Exchange (CME) Live Cattle Futures Contract. A perennial research objective has been to identify which price series causes (or leads) the other (Covey and Bessler, 1992; Mathews et al., 2015; Oellermann and Farris, 1985). Price analysis that focuses on the cash markets for live cattle has examined cointegration and causal relationships among cash markets (Goodwin and Schroeder, 1990, 1991; Pendell and Schroeder, 2006; Schroeder, 1997). To a lesser degree, the dynamics of how information is shared between live cattle cash markets has been considered (Bailey and Brorsen, 1985, 1989; Goodwin and Schroeder, 1990; Pendell and Schroeder, 2006; Schroeder and Goodwin, 1990; Walburger and Foster, 1998). Research in this latter category has been sparse in recent years. Many factors, such as number of live cattle marketed via negotiation, percentage of all live cattle sold by negotiation, and relative volumes of negotiated trade in key feedlot states, have changed over the past several years. Price discovery analysis, which considers the complexities and changes in the negotiated cash markets for live cattle, is needed to fill this space in the literature.

Figure 1 shows the annual average percentage of negotiated sales of live steers and heifers across the five major Livestock Mandatory Price Reporting (LMR) regions. Each region's percentage is calculated as a percent of total marketing in the five regions, forcing the sum of the annual average percentages to sum to $100 \%$. From 2001 to 2015, the relative share of negotiated marketing in Texas declined from being the largest to the smallest among the regions. In the last 2 years, negotiation in Texas has increased, but it remains small relative to earlier levels. Kansas followed a similar, though less severe, trend reaching its low in 2014-2015 and then experiencing a slight increase in negotiation in the last 2 years. Nebraska and Iowa have both increased in their relative 


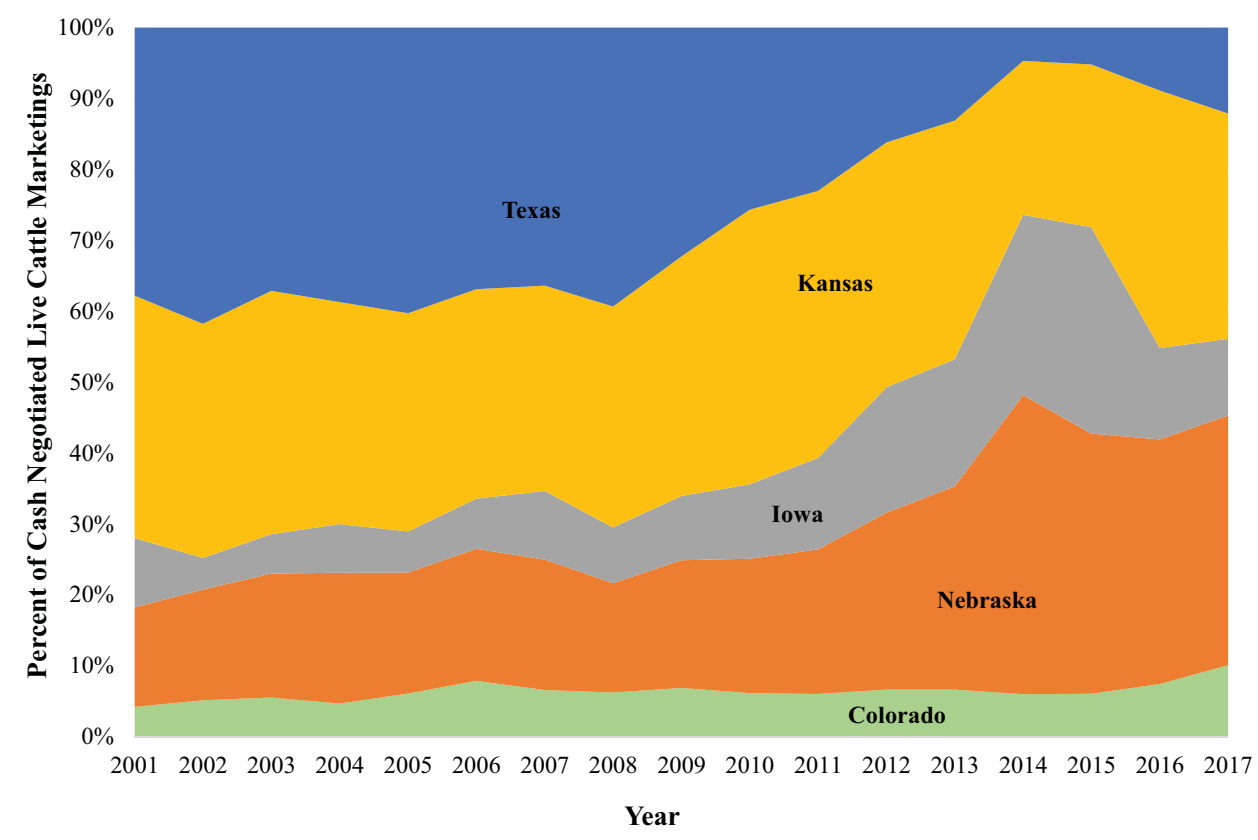

Figure 1. Annual Average Percentage of Negotiated Live Cattle Marketings among Major Livestock Mandatory Price Reporting Regions

shares of the negotiated market. Finally, Colorado's share has remained steady.

Given the shift in the relative volumes of negotiated trade, the roles of regional negotiated live cattle markets have potentially changed as well. Updating knowledge regarding the price discovery relationships between major negotiated live cattle markets will be of value to industry participants, analysts, and policy makers who might examine live cattle market structure issues.

The purpose of this research is twofold. First, we examine price discovery relationships between negotiated live cattle markets in the five major LMR regions (Colorado, Iowa/Minnesota, Kansas, Nebraska, Texas/Oklahoma/New Mexico) since the implementation of LMR. Specifically, we use a vector error correction model (VECM) framework to test for Granger causality among the five markets - that is, how past prices contribute to the understanding of current prices. We go on to use the covariance matrix of VECM innovations to parameterize directed acyclic graph (DAG) analysis of contemporaneous causal relationships among the regions to complement the Granger causality analysis. The use of these methods accomplishes the second purpose-demonstrating how these two price discovery tools can be combined, with consideration given to how live cattle markets function, to reveal nuances in the timing of price discovery in negotiated cash markets for live cattle. Results indicate causal roles among the 
five markets have changed since 2001. In the earlier period, Kansas, Nebraska, and Texas Granger caused prices in other regions. However, from 2010 to 2017, Colorado was the only price series that Granger caused other price series. DAG results show that when within-week information is included, Colorado is the information dump. That is, price information flows to, but not from, Colorado. Taken together, the findings emphasize the value in both techniques to understand nuances of live cattle price discovery. For instance, Colorado, a minor market in terms of relative volume, has apparently assumed a prevalent role in the weekto-week price discovery of other LMR regions.

\section{Price Discovery Analysis}

Price discovery analysis seeks to identify how information is transmitted from one market to another and to what degree markets are integrated with each other. Research specifically focused on live cattle markets has analyzed cash markets to determine how information travels between the regional markets. Price transmission among cash markets was largely symmetric (Bailey and Brorsen, 1989), and price adjustments from shocks occurred with a week or two (Bailey and Brorsen, 1985; Schroeder and Goodwin, 1990). Larger markets tended to dominate the price discovery process (Bailey and Brorsen, 1985; Schroeder and Goodwin, 1990). Koontz, Garcia, and Hudson (1990) found that the price discovery process, including which markets are dominant, is dynamic, depends on the underlying market structures, and changes over time. These findings underscore the importance of updating the understanding of the live cattle price discovery process as the industry evolves.

Identifying the degree of cointegration (Engle and Granger, 1987; Johansen, 1988) between different live cattle markets has been one prominent subset of live cattle price discovery literature. ${ }^{2}$ Schroeder and Goodwin (1990) found limited cointegration among live cattle cash markets during the period of 1980 to 1987 but noted that cointegration among the markets appeared to be growing over time. Later research using slaughter plant transaction data found regional live cattle markets were mostly cointegrated with one another (Schroeder, 1997). After the advent of LMR in 2001, data for regional live cattle markets became more standardized and were made publicly available by the U.S. Department of Agriculture's Agricultural Marketing Service (USDA-AMS). Using pre- and postLMR data, Pendell and Schroeder (2006) found that regional live cattle cash markets became more integrated after the implementation of LMR. Research focusing on how LMR has changed live cattle markets determined that supply and demand responses changed after LMR (Pozo, Bejan, and Tejeda, 2016) and

2 A considerable amount of research has also been done concerning the cointegration of live cattle cash prices with the price of the CME Live Cattle Contract. Mathews et al. (2015) is a recent example, which also provides a summary of past efforts. 
that the LMR did not affect volatility of prices in the Iowa-Minnesota region (Chimai and Chung, 2017).

\section{Methods}

We employ two methods for identifying how information flows between cash markets for live cattle. The first approach is an error correction model (ECM), which is present in the price discovery literature for cattle (Mathews et al., 2015; Stockton, Bessler, and Wilson, 2010), hogs (Franken, Parcell, and Tonsor, 2011), and energy (Saghaian, 2010). The ECM approach allows for cointegration among price series. Next, we use DAG to define linkages between live cattle markets. We use both methods to separate the price discovery dynamics. ECM analysis focuses on how lagged prices affect current prices. Alternatively, DAG considers how contemporaneous price shocks are transmitted among markets. Distinguishing between the innovations because of lagged price shocks and current price shocks is important.

\subsection{Vector Error Correction Model}

Following model selection criteria (Enders, 1995), the VECM was chosen. Using the augmented Dickey Fuller test, these data were found to be nonstationary in levels but stationary in the first differences. ${ }^{3}$ The Johansen cointegration test indicated that the five price series were cointegrated at $r=4{ }^{4}$ That is, four cointegrating vectors exist among the five-price series. This combination suggests a VECM is appropriate. The VECM is specified as

$$
\Delta P_{r, t}=\beta_{0}+\sum_{m} \gamma_{m \neq r} \widehat{\mu}_{m \neq r, t-1}+\sum_{m} \sum_{k=1}^{K} \beta_{m, k} \Delta P_{m, t-k}+\varepsilon_{r, t}
$$

Indices $r$ and $m$ both refer to the five major LMR regions for live cattle prices. The speed of innovation coefficient to be estimated is $\gamma$ and varies across regions. This is a measure of how the price changes in one region respond to price shocks in other regions. Each regional equation has four speed of adjustment coefficients, one for each of the other regions. Lagged errors from the cointegrating equations are represented by $\widehat{\mu}$. This error term $(\widehat{\mu})$ represents the aforementioned price shocks. In other words, it is the deviation between observed price and the portion of price explained by structural component of the regional equation. $\Delta P$ is the lagged price change and is included for $K$ lags in each region. We used Wald tests for lag exclusion to determine that two lags should be included $(K=2)$. $\beta$ s are

3 Results were the same using the Phillips-Perron test.

4 As there are five price series, there can be a maximum of four cointegrating vectors and, therefore, four adjustment coefficients. As explained later, we find including four coinegrating relationships to be appropriate. We chose to use the Texas price series as the dependent variable in each cointegrating equation, with one other cash price series as the independent variable. 
coefficients to be estimated, and $\varepsilon$ is the error term. The vector error correction (VEC) framework allows for a test of Granger noncausality among cointegrated prices (Dolado and Lütkepohl, 1996; Enders, 1995; Toda and Yamamoto, 1995). Prices in region $m$ are said to not Granger cause those in region $r$ if

$$
\beta_{m, 1}=\ldots=\beta_{m, k}=0 .
$$

In other words, if the coefficients on any of the lagged price changes are statistically different from zero, Granger causality is present. In the context of the VEC framework, researchers generally refer to this test as a shortrun relationship. As usual, Granger causality here indicates that knowing past information improves ability to predict future observations.

\subsection{Directed Acyclic Graph Analysis}

DAG analysis is a nonparametric method that provides a picture representing causal flow between price series (Bessler and Davis, 2004) and is appropriate for analyzing cointegrated price series when specified using covariance matrix of errors from the ECM model (Bessler and Davis, 2004; Haigh, Nomikos, and Bessler, 2004; Saghaian, 2010). DAG analysis identifies the causal relationship(s) between variables using an algorithmic approach. One option is the PC algorithm, which begins by assuming a nondirectional relationship between each variable (Spirtes, Glymour, and Scheines, 1993). The relationship is represented graphically by a straight line, or edge, with no arrows. From there, the causal relationship is tested. If a statistically significant partial correlation does not exist, the edge is removed. For statistically significant relationships, the direction of the causal flow is determined (Haigh, Nomikos, and Bessler, 2004; Saghaian, 2010; Spirtes, Glymour, and Scheines, 1993). Ultimately, each pair of variables will be connected by one of three possibilities: (1) no line, which means there is no causal relationship; (2) a line with no arrows, which indicates a relationship, but the directional flow is undetermined; or (3) a line with an arrow, which identifies the direction of the causal flow.

\section{Data}

Live cattle price series were taken from USDA-AMS LMR data, compiled by the Livestock Marketing Information Center. Weekly price data from June 2001 to July 2017 were collected for negotiated live steer and heifer sales in the Colorado, Iowa/Minnesota, Nebraska, Kansas, and Texas/Oklahoma/New Mexico regions. Each region's weekly price is the weighted average of the live steer and heifer prices. ${ }^{5}$ Figure 2 is a plot of weighted average of Kansas negotiated live steer and

5 Because of the federal government shutdown of October 2013, 3 weeks of prices were missing for each region. Prices for these 3 weeks were estimated using the econometric relationships between each region's cash prices and price of nearby CME Live Cattle Contract. 


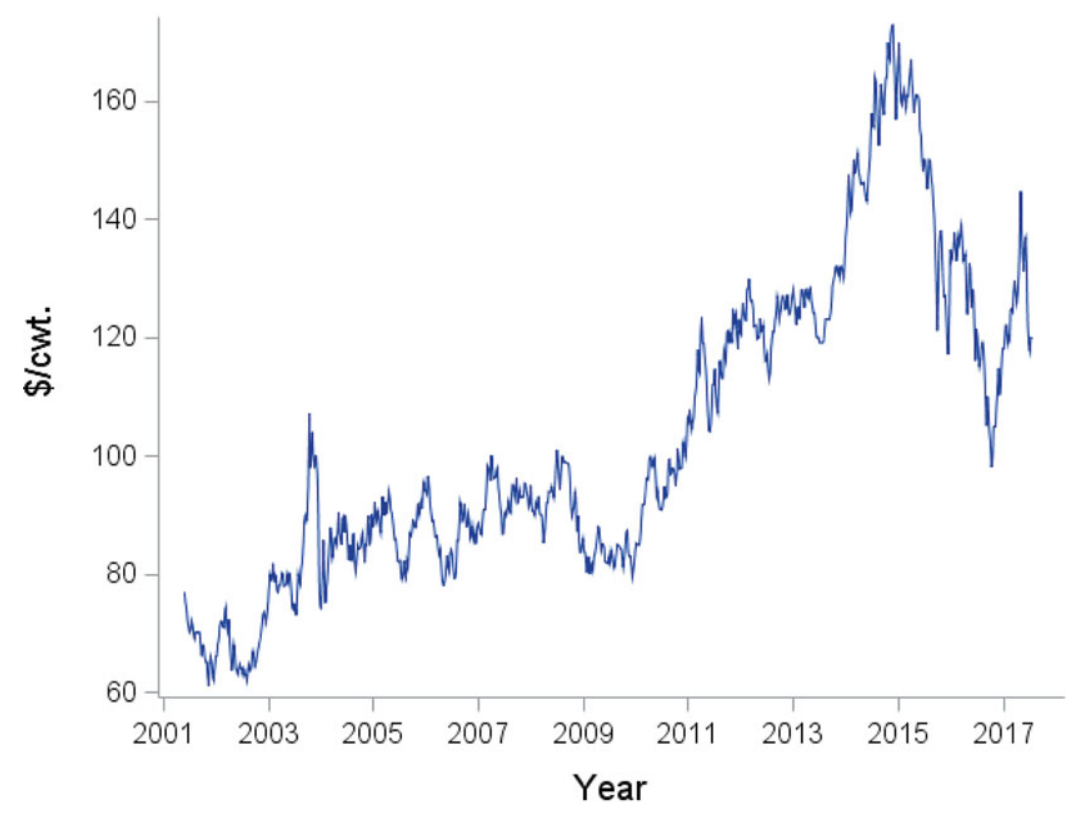

Figure 2. Weighted Average Weekly Negotiated Cash Prices of Slaughter Kansas Steers and Heifers

heifer prices over the time period analyzed. Though there are slight differences, plots of price series from other major reporting regions are similar. Since 2010, live cattle prices have reached higher levels and increased volatility, relative to 2001 to 2009. Based on these differences, we analyze the separate periods of 2001 to 2009 and 2010 to 2017, as well as the entire time period. Similar approaches to divide data based on levels and relative volatility have been used in the price discovery literature for livestock (Mathews et al., 2015) and grains (Arnade and Hoffman, 2015). Summary statistics for the price series are reported in Table 1. Correlations among the price series are shown in Table 2. As expected, cash prices in the five regions are highly correlated. Further, the correlations are similar across both time periods.

\section{Results}

The VECM in equation (1) was specified using USDA-AMS price data assuming four cointegrating relationships. Three separate time periods were considered: 2001 to 2017, 2001 to 2009, and 2010 to 2017. As VEC coefficients are difficult to interpret (Bessler and Davis, 2004), we follow convention in the literature and do not report those directly (Bessler and Davis, 2004; Saghaian, 
Table 1. Descriptive Statistics of Weekly Negotiated Live Cattle Cash Prices

\begin{tabular}{|c|c|c|c|c|c|c|c|}
\hline $\begin{array}{l}\text { Time } \\
\text { Period }\end{array}$ & Region & Mean & $\begin{array}{l}\text { Standard } \\
\text { Deviation }\end{array}$ & $\begin{array}{l}\text { Coefficient } \\
\text { of Variation }\end{array}$ & Minimum & Maximum & $\mathrm{N}$ \\
\hline \multicolumn{8}{|c|}{2001 to 2017} \\
\hline & Colorado & 103.70 & 26.40 & 25.46 & 61.37 & 173.14 & 843 \\
\hline & Iowa & 102.95 & 26.10 & 25.35 & 61.73 & 170.14 & 843 \\
\hline & Kansas & 103.44 & 26.04 & 25.17 & 60.99 & 172.83 & 843 \\
\hline & Nebraska & 103.47 & 26.30 & 25.42 & 61.85 & 172.21 & 843 \\
\hline & Texas & 103.52 & 25.98 & 25.10 & 60.22 & 173.00 & 843 \\
\hline \multicolumn{8}{|c|}{2001 to 2009} \\
\hline & Colorado & 83.63 & 9.65 & 11.54 & 61.37 & 112.58 & 448 \\
\hline & Iowa & 83.07 & 9.42 & 11.34 & 61.73 & 112.42 & 448 \\
\hline & Kansas & 83.66 & 9.60 & 11.47 & 60.99 & 107.08 & 448 \\
\hline & Nebraska & 83.46 & 9.59 & 11.49 & 61.85 & 113.04 & 448 \\
\hline & Texas & 83.75 & 9.63 & 11.49 & 60.22 & 107.30 & 448 \\
\hline \multicolumn{8}{|c|}{2010 to 2017} \\
\hline & Colorado & 126.48 & 20.15 & 15.93 & 83.39 & 173.14 & 395 \\
\hline & Iowa & 125.49 & 19.90 & 15.86 & 83.41 & 170.14 & 395 \\
\hline & Kansas & 125.87 & 19.87 & 15.79 & 84.02 & 172.83 & 395 \\
\hline & Nebraska & 126.16 & 20.07 & 15.91 & 83.22 & 172.21 & 395 \\
\hline & Texas & 125.94 & 19.72 & 15.66 & 85.25 & 173.00 & 395 \\
\hline
\end{tabular}

Table 2. Correlations between Weekly Negotiated Live Cattle Cash Prices

\begin{tabular}{|c|c|c|c|c|c|c|}
\hline Time Period & & Colorado & Iowa & Kansas & Nebraska & Texas \\
\hline \multicolumn{7}{|l|}{2001 to 2017} \\
\hline & Colorado & 1.000 & & & & \\
\hline & Iowa & 0.999 & 1.000 & & & \\
\hline & Kansas & 0.999 & 0.998 & 1.000 & & \\
\hline & Nebraska & 1.000 & 0.999 & 0.999 & 1.000 & \\
\hline & Texas & 0.999 & 0.998 & 1.000 & 0.999 & 1.000 \\
\hline \multicolumn{7}{|l|}{2001 to 2009} \\
\hline & Colorado & 1.000 & & & & \\
\hline & Iowa & 0.991 & 1.000 & & & \\
\hline & Kansas & 0.995 & 0.987 & 1.000 & & \\
\hline & Nebraska & 0.998 & 0.995 & 0.994 & 1.000 & \\
\hline & Texas & 0.995 & 0.986 & 0.998 & 0.993 & 1.000 \\
\hline \multicolumn{7}{|l|}{2010 to 2017} \\
\hline & Colorado & 1.000 & & & & \\
\hline & Iowa & 0.997 & 1.000 & & & \\
\hline & Kansas & 0.999 & 0.996 & 1.000 & & \\
\hline & Nebraska & 0.999 & 0.998 & 0.998 & 1.000 & \\
\hline & Texas & 0.998 & 0.996 & 1.000 & 0.998 & 1.000 \\
\hline
\end{tabular}


Table 3. Vector Error Correction Model (VECM) Granger Causality/Block Exogeneity Wald Tests with Two Lags

\begin{tabular}{|c|c|c|c|c|}
\hline \multirow[b]{2}{*}{$\begin{array}{l}\text { Dependent Price } \\
\text { Series }\end{array}$} & \multirow[b]{2}{*}{$\begin{array}{l}\text { Excluded/Independent } \\
\text { Price Series }\end{array}$} & \multicolumn{3}{|c|}{ Chi-Square Test Statistic } \\
\hline & & $\begin{array}{l}2001 \text { to } \\
2017\end{array}$ & $\begin{array}{l}2001 \text { to } \\
2009\end{array}$ & $\begin{array}{l}2010 \text { to } \\
2017\end{array}$ \\
\hline \multirow[t]{4}{*}{ Colorado } & Iowa & 1.01 & 4.31 & 0.65 \\
\hline & Kansas & 3.98 & $7.85^{* *}$ & 1.83 \\
\hline & Nebraska & $6.00^{* *}$ & $7.06^{* *}$ & 0.68 \\
\hline & Texas & $5.97^{*}$ & 3.80 & 1.40 \\
\hline \multirow[t]{4}{*}{ Iowa } & Colorado & $10.37^{* *}$ & 1.42 & $7.59^{* *}$ \\
\hline & Kansas & $7.67^{* *}$ & $8.41^{* *}$ & 1.90 \\
\hline & Nebraska & $8.57^{* *}$ & $4.63^{*}$ & 3.12 \\
\hline & Texas & $9.08^{* *}$ & $6.27^{* *}$ & 2.18 \\
\hline \multirow[t]{4}{*}{ Kansas } & Colorado & $9.62^{* *}$ & 1.45 & $7.17^{* *}$ \\
\hline & Iowa & 0.13 & 2.54 & 1.83 \\
\hline & Nebraska & 3.11 & 3.53 & 0.97 \\
\hline & Texas & $9.52^{* *}$ & $8.64^{* *}$ & 1.43 \\
\hline \multirow[t]{4}{*}{ Nebraska } & Colorado & $9.70^{* *}$ & 1.73 & $7.79^{* *}$ \\
\hline & Iowa & 0.94 & $5.25^{*}$ & 1.58 \\
\hline & Kansas & 2.64 & $6.07^{* *}$ & 2.58 \\
\hline & Texas & $5.63^{*}$ & $5.65^{*}$ & 1.42 \\
\hline \multirow[t]{4}{*}{ Texas } & Colorado & $9.70^{* *}$ & 1.73 & $7.79^{* *}$ \\
\hline & Iowa & 0.94 & $5.25^{*}$ & 1.58 \\
\hline & Kansas & 2.64 & $6.07^{* *}$ & 2.58 \\
\hline & Nebraska & $5.63^{*}$ & $5.65^{*}$ & 1.42 \\
\hline
\end{tabular}

Notes: Results are based on results from a VECM that included all five price series as endogenous variables. Each group of test statistics is based on the VECM equation with that particular price series as the dependent variable. Asterisks $\left({ }^{* *}\right.$ and ${ }^{*}$ ) represent statistical significance at the 0.05 and 0.10 levels, respectively.

2010; Stockton, Bessler, and Wilson, 2010). ${ }^{6}$ Instead, we focus on the causal relationships identified by the VEC estimates using equation (2). Chi-square test statistics for all causality tests are reported in Table 3.

The Granger causal relationships between the five live cattle cash markets differ over time. In the first period, between 2001 and 2009, Kansas was primary source of price information as it was found to Granger cause all other price series. However, Kansas did not lead any other markets in the more recent period of 2010 to 2017. Nebraska and Texas were also important sources of price discovery information from 2001 to 2009. Unlike Kansas, these two markets also lead multiple other markets when the analysis was broadened to include 2001 to 2017. Perhaps the starkest difference between time periods is the impact of Colorado prices on other markets. Over the entire sample, and in the recent time of 2010 to 2017, Colorado Granger caused prices in all four other regions.

6 The complete VECM estimation results are available upon request from the authors. 
However, when the analysis focused on the years 2001 to 2010, Colorado did not lead prices for any other region. Another notable finding is that during 2010 to 2017, Colorado was the only market that Granger caused other price series.

Some of these changes correspond to changes the relative volumes of negotiated sales in the five major LMR regions. As the relative number of transactions in the Texas, and to a lesser degree Kansas, negotiated market have declined (see Figure 1), it would be reasonable to assume that the causal role of these markets has lessened over time. However, other differences are more difficult to reconcile with market conditions. For example, the negotiated live cattle market in Nebraska has grown, relative to the other four markets, but its causal effects disappeared in the 2010 to 2017 model. Further, Colorado has often represented less than $10 \%$ of the negotiated trade of the five regions but leads all other price series in 2010 to 2017.

When interpreting these results, it is helpful to remember that Granger causality is strictly measuring the usefulness of lagged information in explaining current information. Putting this in the language of live cattle price discovery and this research, Granger causality exists if one or both of the previous 2 weeks' prices from one region statistically explain current prices in another region. However, weekly live cattle prices in different regions are not determined simultaneously. Bids and offers occur during the week with some regions trading earlier in the week than others. That means that the price information flow between markets during a given week could be an important part of live cattle price discovery that is overlooked by focusing only on Granger causal relationships.

DAG analysis complements Granger causality analysis by providing a picture of causal flow of price information, including contemporaneous information and without imposing a functional form or other restrictions (Bessler and Davis, 2004; Haigh, Nomikos, and Bessler, 2004; Saghaian, 2010). The covariances of the full VECM errors (innovations) are shown in Table 4. The variances and covariances of the VEC errors are noticeably greater in the later time period. These covariance matrices of the VECM were used to parameterize DAG analysis of the price series. ${ }^{7}$

Figure 3 is a DAG of the live cattle price series from 2001 to 2017. In this case, every remaining edge has a direction identified at the 0.01 level. ${ }^{8}$ As explained, the line with an arrow shows the causal flow of price information. For example, price information flows from the Iowa market to Colorado and Nebraska. With two arrows flowing away from it, the Iowa market is a stronger source of price

7 DAG analysis was conducted using the PC algorithm in TETRAD VI (Glymour et al., 2015).

8 As explained by Bessler and Davis (2004), extensive Monte Carlo experimentation has shown that, in practice, significance levels for DAG analysis should have an inverse relationship with sample size (Spirtes, Glymour, and Scheines, 1993). As we have relatively large sample sizes, we opt for a small significance level of 0.01 and maintain that for all iterations to facilitate comparison. 
Table 4. Covariance Matrices of Vector Error Correction Model Innovations

\begin{tabular}{|c|c|c|c|c|c|c|}
\hline Time Period & & Colorado & Iowa & Kansas & Nebraska & Texas \\
\hline \multicolumn{7}{|l|}{2001 to 2017} \\
\hline & Colorado & 6.403 & & & & \\
\hline & Iowa & 5.282 & 5.238 & & & \\
\hline & Kansas & 5.675 & 4.955 & 5.722 & & \\
\hline & Nebraska & 6.091 & 5.424 & 5.611 & 6.167 & \\
\hline & Texas & 5.605 & 4.843 & 5.459 & 5.495 & 5.516 \\
\hline \multicolumn{7}{|l|}{2001 to 2009} \\
\hline & Colorado & 4.171 & & & & \\
\hline & Iowa & 3.599 & 3.846 & & & \\
\hline & Kansas & 3.919 & 3.646 & 4.417 & & \\
\hline & Nebraska & 4.055 & 3.808 & 3.998 & 4.197 & \\
\hline & Texas & 3.879 & 3.452 & 4.015 & 3.844 & 3.990 \\
\hline \multicolumn{7}{|l|}{2010 to 2017} \\
\hline & Colorado & 8.321 & & & & \\
\hline & Iowa & 6.668 & 6.362 & & & \\
\hline & Kansas & 7.152 & 5.983 & 6.744 & & \\
\hline & Nebraska & 7.842 & 6.776 & 6.969 & 7.879 & \\
\hline & Texas & 7.005 & 5.942 & 6.595 & 6.867 & 6.682 \\
\hline
\end{tabular}

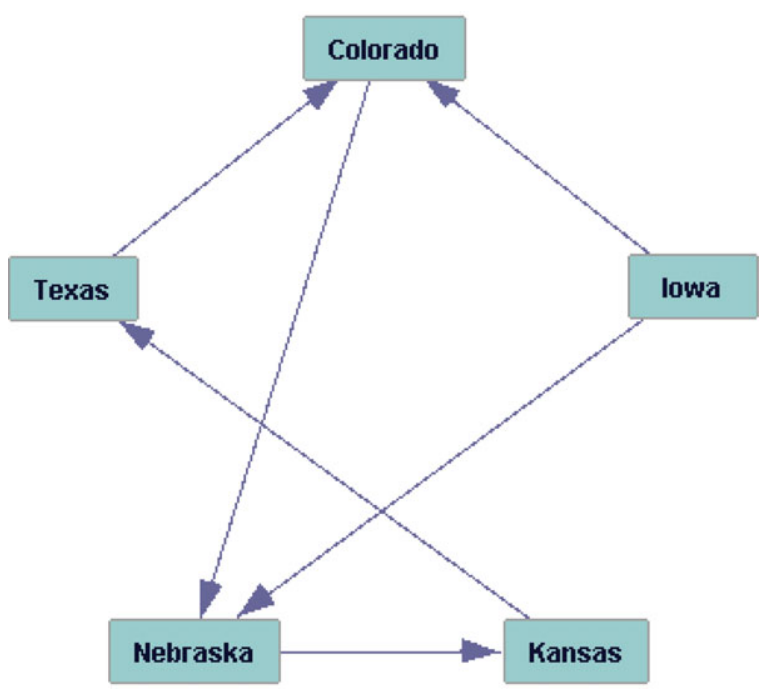

Figure 3. Directed Acyclic Graph of Cash Negotiated Live Cattle Prices from 2001 to 2017 (note: graph generated with TETRAD 6.3.4 software using the $\mathrm{PC}$ algorithm at $P=0.01$ ) 


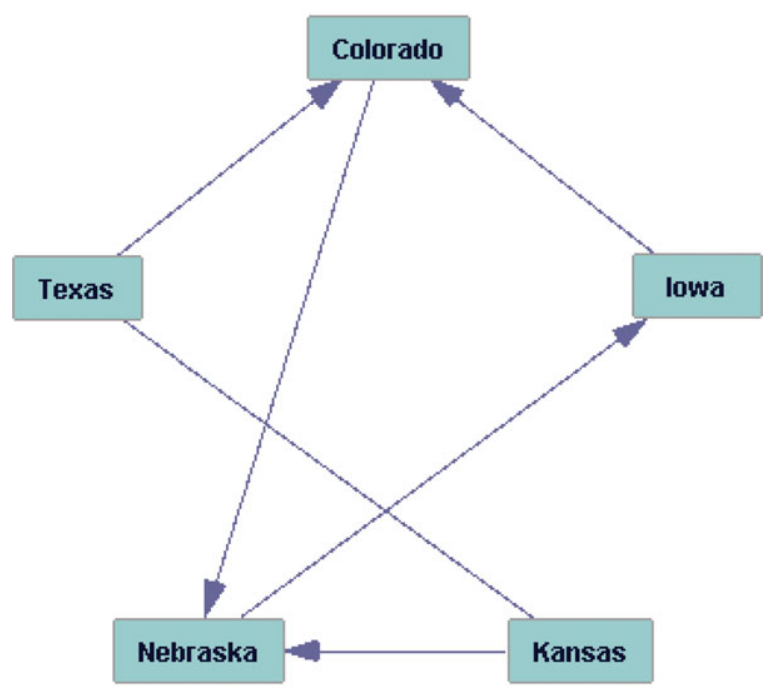

Figure 4. Directed Acyclic Graph of Cash Negotiated Live Cattle Prices from 2001 to 2009 (note: graph generated with TETRAD 6.3.4 software using the PC algorithm at $P=0.01$ )

information than any of the other four markets. Notice that this is the opposite of the Granger causality findings (Table 3 ) where lagged Iowa prices did not lead any other market. In fact, from 2001 to 2017, Iowa prices are the most dependent on the lagged prices of other markets as Iowa is the only price series that is Granger caused by all four other markets. This difference illustrates that value of using both methods as proposed in this study. Having absorbed the price information of lagged prices of other markets, Iowa prices became an important causal price series for within-week prices, as revealed by DAG. This potentially fits with bidding behavior in the negotiated cash market for live cattle. If Iowa bids and offers are based on past prices in other regions, cattle trade could occur early in the week in Iowa. Following this, other markets could use the Iowa trade to set prices for that week. The causal role of the Iowa market was different over the period, depending on whether lagged or contemporaneous prices were included.

Figures 4 and 5 show DAG results for 2001 to 2009 and 2010 to 2017, respectively. Although, the DAG for 2001 to 2009 is similar to the figure for the entire period, there are three differences between the time periods. The Nebraska prices caused Iowa prices, Kansas prices cause Nebraska prices, and the relationship between Texas and Kansas has no direction assigned. The DAG for 2010 to 2017 (Figure 5) has only three directed edges. This implies that the within-week causal relationships were less well defined, relative to 2001 to 2009 where five directional relationships were identified. In the case of the most recent 


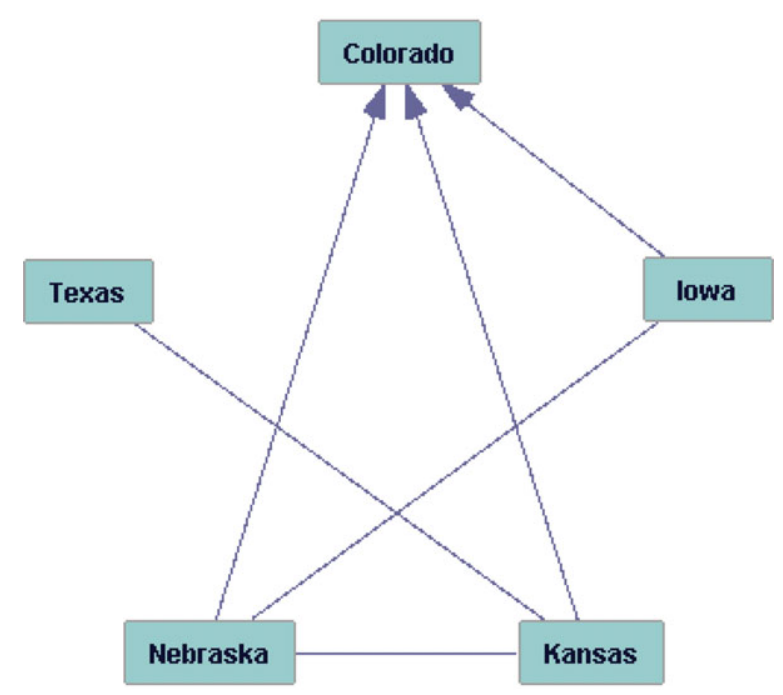

Figure 5. Directed Acyclic Graph of Cash Negotiated Live Cattle Prices from 2010 to 2017 (note: graph generated with TETRAD 6.3.4 software using the PC algorithm at $P=0.01$ )

time period, Colorado is an information dump. That is, information only flows into Colorado. Again, this is in contrast to the Granger causality results for the same period (Table 3) that show Colorado prices leading all other markets. However, finding different conclusions with the VECM approach versus DAG does not mean that either is necessarily incorrect (Saghaian, 2010). In the case of live cattle negotiated markets, this finding has an intuitive appeal. If Colorado is absorbing within-week price information, then that means cattle are likely trading there late in the week, after other markets have traded. If that is the case, Colorado prices from a previous week will contain the most and most recent information of any market and will be used by other markets to set bids and offers early in the week. ${ }^{9}$ Again, the Colorado price series has a different causal role depending on whether lagged or within-week prices are considered.

A final point to note regarding the interpretation of these results is the difference in price movements in 2001 to 2009 compared with 2010 to 2017. Live cattle prices experienced an unprecedented bullish trend between 2010 and 2015. Both the Granger causality and DAG results are extreme compared with

9 At the suggestion of a reviewer, we performed a basic analysis of daily LMR data. The percentage of negotiated live and dressed cashed sales occurring on Friday increased in Colorado from $37 \%$ to $41 \%$ from the early period to the later period. In Kansas, the same measure decreased from $44 \%$ to $38 \%$, while Wednesday sales increased from $18 \%$ to $23 \%$. This suggests there are regional differences in how negotiated live cattle markets are evolving, regarding within-week behavior. Further research similar to the current study, which analyzes daily data, could be informative. 
other model iterations. ${ }^{10}$ Specifically, Colorado is the only region to Granger cause other regions, and all three directed edges present in the DAG flow into Colorado. Though the current analysis does not allow us to statistically test this, these extremes in price discovery could be more likely to occur in such a bullish market. If sellers' default assumption is that prices are trending upward, then waiting until later in the week to sell would be rational. Cattle feeders in Colorado, a relatively smaller market, might base prices on trade in the relatively larger markets of Iowa, Nebraska, and Kansas. These same larger markets would then find the Colorado prices to be a starting point for the following week. At the same time, causal relationships between other markets existed, but the direction of information was unclear, suggesting the price discovery process in 2001 to 2009 differed from that of 2010 to 2017. Using VEC and DAG analysis together reveals these nuances.

\section{Conclusions}

This study used a VEC framework to determine Granger causality among live cattle prices in the five major LMR regions. The covariance matrix of the VEC errors was then used to parameterize DAG analysis of the same prices. Using both techniques allows assessment of how lagged and contemporaneous causality compare. Results show that lagged and contemporary causal relationships in live cattle price discovery have changed over time. Analyzing prices in the periods of 2001 to 2017 and 2001 to 2009 shows the five markets to be more connected by causal relationships than when the later period of 2010 to 2017 is isolated. Further, causal roles of markets differ depending on whether lagged (Granger causality in the VEC framework) or contemporaneous (DAG analysis) prices are considered. Results of this study emphasize the importance of understanding nuances of underlying markets and empirical techniques in price discovery analysis. Readers should note the limitations of the methods utilized in this study, as with other price discovery research cited, and interpret results accordingly. That is, we are able to measure statistical relationships between price series but interpret results to draw conclusions about price discovery activity. However, fit with conventional wisdom concerning live cattle markets and robustness of results (see footnote 9) adds credibility to our findings.

The share of live cattle marketed via cash negotiation continues to decline. At the same time, formula sales, which often depend on LMR negotiated prices, continue to grow. These two trends suggest that though use of negotiation as a live cattle marketing method is decreasing, the importance of negotiated

10 As pointed out by a reviewer, there is always the possibility of spurious relationships in this type of analysis. However, specifying the model over different time periods yielded similar results, which gives some evidence of robustness of results. We note this as a caution and to suggest that further analysis of changing price dynamics is an area of future research worthy of attention. 
prices to broader price discovery is not (Schroeder, Tonsor, and Coffey, 2018). Results of this study show that price information flow among cash markets has changed over the years. For example, the seemingly minor Colorado market actually played a major price discovery role from 2010 to 2017 . If the results of this research are reflective of price discovery behavior in live cattle markets, participants in Iowa, Nebraska, Kansas, and Texas benefit from the Colorado prices and the information therein. As LMR evolves, consideration should be given to how this price discovery "work" being done in one region is used in another. For example, will it be appropriate, at some point, to compensate regions that negotiate and provide the information to other regions? If so, can this be accomplished without distorting markets?

Continued research is needed in this area and in analyzing why the five live cattle cash markets were less connected in 2010 to 2017 than in previous years and what the implications of this decrease in connectedness are. One area of needed research implied by our findings is how the similarity or dissimilarity of cattle in the Colorado market compared with the broader U.S. market might affect price discovery in the formula priced or forward contracted cattle. If Colorado prices influence week-to-week negotiated cash prices, it is reasonable to assume that they also influence formula prices (i.e., they might be used a base price). If this is the case, then a relatively small market is indeed pricing a large number of cattle. Presently, it is not clear how this might affect price discovery positively or negatively. However, the findings of this study indicate more research is warranted.

\section{References}

Arnade, C., and L. Hoffman. "The Impact of Price Variability on Cash/Futures Market Relationships: Implications for Market Efficiency and Price Discovery." Journal of Agricultural and Applied Economics 47,4(2015):539-59.

Bailey, D., and B.W. Brorsen. "Dynamics of Regional Fed Cattle Prices." Western Journal of Agricultural Economics 10,1(1985):126-33.

_. "Price Asymmetry in Spatial Fed Cattle Markets." Western Journal of Agricultural Economics 14,2(1989):246-52.

Bessler, D.A., and E.E. Davis. "Price Discovery in the Texas Cash Cattle Market." Applied Stochastic Models in Business and Industry 20,4(2004):355-78.

Chimai, B., and C. Chung. "Effects of Livestock Mandatory Reporting on Fed Cattle Spot Market Price Volatility: Evidences from United States Regional Cattle Markets.” Paper presented at the Agricultural and Applied Economics Association's 2017 AAEA Annual Meeting, Chicago, Illinois, July 30-August 1, 2017. Internet site: http://ageconsearch. umn.edu/record/259958/files/Abstracts_17_07_11_16_38_47_85_172_16_20_110_ 0.pdf (Accessed July 19, 2018).

Covey, T., and D.A. Bessler. "Testing for Granger's Full Causality." Review of Economics and Statistics 74,1(1992):146-53.

Dolado, J.J., and H. Lütkepohl. "Making Wald Tests Work for Cointegrated VAR Systems." Econometric Reviews 15,4(1996):369-86. 
Enders, W. Applied Econometric Time Series. New York: Wiley, 1995.

Engle, R.F., and C.W.J. Granger. "Co-Integration and Error Correction: Representation, Estimation, and Testing.” Econometrica 55,2(1987):251-76.

Franken, J.R.V., J.L. Parcell, and G.T. Tonsor. "Impact of Mandatory Price Reporting on Hog Market Integration.” Journal of Agricultural and Applied Economics 43,2(2011):22941.

Glymour, C., R. Scheines, P. Sprites, and J. Ramsey. TETRAD V Software and User's Manual. Pittsburgh, PA: Department of Philosophy, Carnegie Mellon University, 2015. Internet site: http://www.phil.cmu.edu/tetrad/ (Accessed December 22, 2017).

Goodwin, B.K., and T.C. Schroeder. "Cointegration Tests and Spatial Price Linkages in Regional Cattle Markets.” American Journal of Agricultural Economics 73,2(1991):45264.

. "Testing Perfect Spatial Market Integration: An Application to Regional U.S. Cattle Markets.” North Central Journal of Agricultural Economics 12,2(1990):173-86.

Haigh, M.S., N.K. Nomikos, and D.A. Bessler. "Integration and Causality in International Freight Markets: Modeling with Error Correction and Directed Acyclic Graphs.” Southern Economic Journal 71,1(2004):145-62.

Johansen, S. "Statistical Analysis of Cointegration Vectors." Journal of Economic Dynamics and Control 12,2(1988):231-54.

Koontz, S.R., P. Garcia, and M.A. Hudson. "Dominant-Satellite Relationships between Live Cattle Cash and Futures Markets." Journal of Futures Markets 10,2(1990):123-36.

Mathews, K.H. Jr., W. Brorsen, W.F. Hahn, C. Arnade, and E. Dohlman. Mandatory Price Reporting, Market Efficiency, and Price Discovery in Livestock Markets. Washington, DC: U.S. Department of Agriculture, Economic Research Service, LDPM254-01, 2015. Internet site: https://www.ers.usda.gov/webdocs/publications/37626/ 53727_ldpm-254-01.pdf?v=0 (Accessed October 27, 2018).

Oellermann, C.M., and P.L. Farris. "Futures or Cash: Which Market Leads Live Beef Cattle Prices?" Journal of Futures Markets 5,4(1985):529-38.

Parcell, J., G.T. Tonsor, and T.C. Schroeder. Baseline Study of Livestock and Meat Marketing Trends and Implications for Livestock Mandatory Reporting. Washington, DC: U.S. Department of Agriculture, Agricultural Marketing Service, 2016. Internet site: https:// www.ams.usda.gov/sites/default/files/media/BaselineStudyLivestockMeatMarketingTre ndsLMR.PDF (Accessed July 19, 2018).

Pendell, D.L., and T.C. Schroeder. "Impact of Mandatory Price Reporting on Fed Cattle Market Integration." Journal of Agricultural and Resource Economics 31,3(2006):56879.

Pozo, V.F., V. Bejan, and H. Tejeda, eds. "Disentangling Supply and Demand Shocks to Identify Changes in the Live Cattle's Market Structure Post Livestock Mandatory Price Reporting Act." Paper presented at the 2016 Agricultural and Applied Economics Association Annual Meeting, Boston, Massachusetts, July 31-August 2, 2016. Internet site: http://ageconsearch.umn.edu/record/236234/files/Pozo_Bejan_ Tejeda_2016.pdf (Accessed July 19, 2018).

Saghaian, S.H. "The Impact of the Oil Sector on Commodity Prices: Correlation or Causation?" Journal of Agricultural and Applied Economics 42,3(2010):477-85.

Schroeder, T.C. "Fed Cattle Spatial Transactions Price Relationships." Journal of Agricultural and Applied Economics 29,2(1997):347-62.

Schroeder, T.C., and B.K. Goodwin. "Regional Fed Cattle Price Dynamics.” Western Journal of Agricultural Economics 15,1(1990):111-22. 
Schroeder, T.C., G.T. Tonsor, and B.K. Coffey. "Commodity Futures with Thinly Traded Cash Markets: The Case of Live Cattle." Journal of Commodity Markets (2018). doi:10.1016/j.jcomm.2018.09.005.

Spirtes, P., C. Glymour, and R. Scheines. Causation, Prediction, and Search. New York: Springer-Verlag, 1993.

Stockton, M.C., D.A. Bessler, and R.K. Wilson. "Price Discovery in Nebraska Cattle Markets.” Journal of Agricultural and Applied Economics 42,1(2010):1-14.

Toda, H.Y., and T. Yamamoto. "Statistical Inference in Vector Autoregressions with Possibly Integrated Processes.” Journal of Econometrics 66,1(1995):225-50.

Walburger, A.M., and K.A. Foster. "Determination of Focal Pricing Regions for U.S. Fed Cattle." American Journal of Agricultural Economics 80,1(1998):84-95. 